\title{
Green coal development for application in fixed-bed catalytic gasification
}

\author{
by J.R. Bunt, S. Marx, F.B. Waanders, and N.T. Leokaoke
}

\section{Synopsis}

A novel 'green coal' product formulation has recently been developed and the utilization concept tested at the North-West University coal research laboratories. Hydrothermal liquefaction was used to produce bio-oil and biomass char from sweet sorghum bagasse at operating temperatures ranging between 280 and $300^{\circ} \mathrm{C}$, and the resultant char was mixed in various ratios $(0,0.25,0.50,0.75$, and 1$)$ with fine medium-rank $\mathrm{C}$ bituminous discard coal $(<212 \mu \mathrm{m})$ and $\mathrm{CaCO}_{3}(1-5 \mathrm{wt} \%)$. The mixtures were pressed into $12 \times 12 \mathrm{~mm}$ pellets using an LRX press at a pressure of 4 bar and gasified using $\mathrm{CO}_{2}$ at atmospheric pressure and temperatures ranging between 800 and $1000^{\circ} \mathrm{C}$. Kinetic parameters obtained from the experimental data showed that the reaction rate of the biochar was an order of magnitude higher than that of raw coal, with the blend containing $3 \mathrm{wt} \%$ $\mathrm{CaCO}_{3}$ having the fastest reaction rate. In order to study the effect of temperature and catalyst on the retention of elemental sulphur during combustion of the various pellets, a combustion set-up consisting of a furnace, glass bayonet-type reactor, Liebig cooler, liquid traps, and an $\mathrm{SO}_{2}$ gas analyser was used, with experiments conducted at temperatures between 500 and $800^{\circ} \mathrm{C}$. As expected, sulphur retention was low for the raw coal and biochar blends, but increased significantly to between 56 and $86 \%$, decreasing with increasing temperature, in the runs with added metal catalyst/sorbent. A simulation using FactSage $\mathrm{TM}^{\mathrm{TM}}$ predicted that $>50 \%$ of the pyritic sulphur entering the fixed-bed gasifier would be removed from the gaseous phase as insoluble $\mathrm{CaSO}_{4}$ when operated in a catalytic gasification mode at a temperature of $800^{\circ} \mathrm{C}$, which is in good agreement with the experimental findings.

Keywords

Coal briquette, catalytic gasification, reactivity, sulphur retention.

\section{Introduction}

The World Energy Outlook in 2011 estimated that global energy needs will increase by $75 \%$ by 2035 , and over 1 trillion US dollars is needed for large-scale investment for future energy supply in coal and biofuels (Statistics SA, 2011). Of the $255 \mathrm{Mt}$ of coal produced annually in South Africa, $60 \mathrm{Mt}$ is discarded from mining and transport operations because of its perceived poor quality (high ash and sulphur), and volatiles diminish as stockpiles age (Wagner, 2008; Bunt and van Nierop, 1997). Coal fines, generally classified as particles $<500 \mu \mathrm{m}$ that are separated from the coal during the beneficiation process (UNFCCC, 2001), are also discarded. In coal-to-liquid (CTL) plants, for example, fixed-bed gasifiers use a lower cut size of 5 to $8 \mathrm{~mm}$ in the production of liquid fuels, thereby delivering a higher percentage of 'fine' coal, which is mainly used in the generation of high-pressure steam (in pulverized fuel combustion plants) for use in the gasification process (RatafiaBrown et al., 2002). However, there is an overbalance of fine coal in the circuit, which inevitably leads to coal being discarded into storage ponds and slimes dams (EUBA, 2007).

Since coal is a non-renewable resource, it is important that these coal fines be utilizd. Discard coal with a heating value of approximately $16 \mathrm{MJ} / \mathrm{kg}$ can be burnt by energy utilities, making it a viable energy source; it can be beneficiated and added back to a washed coarser product where contracts allow; or it could be gasified in fluidized-bed and entrained flow reactors. However these technologies are extremely capital-intensive and to date have not been implemented in South Africa (Radloff, Kirsten, and Anderson, 2004; Hippo and Tandon, 1986). The Highveld coalfields are of great importance to the longterm production of synthetic fuel in South Africa, but these coalfields are close to exhaustion, with an estimated remaining recoverable coal reserve of $9 \mathrm{Gt}$ (Jeffrey, 2005). Utilization of discarded Highveld fines will assist in increasing the coal reserves available, and will also be aligned with government policy. An alternative process should therefore be sought to enable coal to be used more effectively, thereby improving the lifespan of coal resources for the benefit of future generations (UNFCCC, 2001).

Coal utilization has also led to rising concerns about $\mathrm{CO}_{2}$ emissions causing global climate change. Biomass is considered to be a renewable resource, and its use assists in reducing $\mathrm{CO}_{2}$ emissions compared with coal, because biomass is suggested to be $\mathrm{CO}_{2}$ neutral with regard to the greenhouse gas balance (Usón et al., 2004; Zhu, Song, and Lin, 2008; Biagini et al., 2002). Carbonization

* North-West University, Potchefstroom, South Africa.

(c) The Southern African Institute of Mining and Metallurgy, 2018. ISSN 2225-6253. Paper received May 2017; revised paper received Dec. 2017. 


\section{Green coal development for application in fixed-bed catalytic gasification}

(also referred to as torrefaction or liquefaction) is a mild thermochemical treatment $\left(200-400^{\circ} \mathrm{C}\right.$ and 100 bar pressure) that removes moisture and organic acids from the biomass, producing a coal-like substance (biochar) as solid product, as well as bio-oil and biogas. The main aim of liquefaction is to transform a material of low density and energy value into a stable product with high energy density and carbon content ready for use in combustion and gasification processes (Chen et al., 2009; Bridgman et al., 2008). Liquefaction entails the highest net energy gain for biomass conversion to solid, liquid, and gas products compared to pyrolysis and gasification (Khoo et al., 2013).

An attractive system for coal gasification is one in which high-sulphur coal is gasified and sulphur in the coal is retained within the gasifier ash, thereby eliminating the need for gas clean-up; i.e. the gas is available for use without first cooling it to preserve the sensible energy; and water vapour is retained in the product gas to make a substantial contribution in the combined-cycle power output. These criteria can be met through the use of a calcium-based sorbent such as limestone or dolomite directly in a fluidizedbed gasifier, which acts as both a catalyst for the gasification reactions and captures sulphur as calcium sulphate

(Abbasian et al., 1990). Researchers in the field of chemical kinetics of limestone/dolomite reactions with hydrogen sulphide (Rehmat et al., 1987; Chang. and Thodos, 1984; Keairns et. al., 1976; Borgwardt, Roache, and Bruce, 1984; Pell, 1971; Squires, Graff, and Pell, 1971; Freund, 1984; Ruth, Squires, and Graff, 1972; Kamath and Petrie, 1981; Borgwardt and Roache, 1984) have verified the potential use of these sorbents for sulphur capture. The reaction of calcined limestone/dolomite is very rapid, and closely approaches equilibrium. On that basis, it is possible to capture substantial quantities of sulphur and discharge it with the ash (Jones and Patel, 1985). Based on equilibrium considerations, it is feasible to remove up to $90 \%$ sulphur using this process.

Much laboratory research has been conducted in the field of catalytic gasification, where small coal particles $(<1 \mathrm{~mm})$ are gasified using steam and $\mathrm{CO}_{2}$ in the presence of alkali metals, and has shown that gasification reactivity can be significantly enhanced at temperatures ranging from 800 $1000^{\circ} \mathrm{C}$. Exxon Research and Engineering Company developed a catalytic coal gasification (CCG) process in the 1970s (Nahas, 1983). More recent research by Nel et al., (2013) has shown that the addition of an impregnated $\mathrm{K}_{2} \mathrm{CO}_{3}$ catalyst (1\% loading) to $10 \mathrm{~mm}$ particles of run-of-mine Highveld coal, lowered the activation energy during reactivity testing compared to raw coal. The challenge remains to increase the catalyst loading to large coal particles. Bunt et al., (2015) successfully demonstrated that a catalyst (1\%, $3 \%, 5 \% \mathrm{~K}_{2} \mathrm{CO}_{3}$ addition) can be incorporated into a discard Highveld fine coal agglomerate mixture (10 mm pellets) by physical mixing in order to improve $\mathrm{CO}_{2}$ gasification reactivity at high temperatures $\left(900-1000^{\circ} \mathrm{C}\right)$. It was concluded that the $\mathrm{CO}_{2}$ gasification reactivity could at least be doubled in this catalysed system compared to raw coal.

From the foregoing it is clear that there is a need to explore the agglomeration of fine discard coal together with biochar and an alkali metal catalyst/sorbent for use in applications such as fixed-bed gasification. A reduction in sulphur emission concomitant with increased reactivity rate will be an improvement over the conventional fixed-bed gasification operation. This paper addresses the development of a 'green coal' formulation and discusses preliminary results obtained from $\mathrm{CO}_{2}$ gasification and carbon combustion tests, thereby demonstrating the ability to enhance the reaction rate and sulphur capturing propensity during thermal treatment.

A number of reactions occur in a fixed-bed gasifier. The gasification reactions are: $\mathrm{H}_{2} \mathrm{O}+\mathrm{C} \rightarrow \mathrm{H}_{2}+\mathrm{CO}$ and $\mathrm{CO}_{2}+\mathrm{C} \rightarrow$ $2 \mathrm{CO}$. We have selected the $\mathrm{CO}_{2}$ gasification reaction with $\mathrm{C}$ as an example in our study. The combustion reaction $\mathrm{C}+\mathrm{O}_{2} \rightarrow$ $\mathrm{CO}_{2}$ was also selected in order to show the impact on $\mathrm{S}$ behaviour in the oxidation zone of the fixed-bed gasifier. Oxygen is needed to drive the endothermic gasification reactions higher up in the gasifier. The $\mathrm{SO}_{2} / \mathrm{SO}_{3}$ generated in the oxidation step flows upwards countercurrent to the downward-moving char bed and reacts with hydrogen produced from the reaction with steam, forming $\mathrm{H}_{2} \mathrm{~S}$ in the top half of the gasifier, which operates under reducing conditions. By sorbent capturing of $\mathrm{S}$ in the form of $\mathrm{CaSO}_{4}$ in the oxidation zone of the gasifier, the $\mathrm{S}$ species is removed from the gasifier with the ash assemblage, resulting in less $\mathrm{H}_{2} \mathrm{~S}$ reporting to the raw synthesis gas. Future work needs to be conducted using the green coal formulation to address the steam gasification reaction and its effect on the reaction rate and sulphur capturing propensity.

\section{Experimental procedure}

\section{Green coal pellet preparation}

Biochar was produced in a grade 316 stainless steel autoclave equipped with removable heating jackets and a magnetic stirrer. The set-up can be seen in Figure 1. Pulverized sweet sorghum bagasse (32.5 g) and distilled water (102 g) were placed in the autoclave. The autoclave was sealed and air was purged using nitrogen. The two heating jackets were tightened and turned on. The magnetic stirrer was set to 50 $\mathrm{r} / \mathrm{min}$ and remained at a constant speed throughout the run. The temperature was allowed to rise to $290^{\circ} \mathrm{C}$ at a heating rate of $2.5 \mathrm{~K} / \mathrm{min}$, whereafter the heating jackets and mechanical stirrer were turned off. The heating jackets were opened and the autoclave was allowed to cool to atmospheric temperature and pressure. An electric fan was used to accelerate the cooling process. Chloroform $(100 \mathrm{ml})$ was added to the autoclave after it had reached ambient temperature and the mixture was stirred for approximately 10 minutes. Chloroform acts as a solvent and aids in the extraction of liquefaction products. The products were separated using a vacuum filter. The liquid product (a mixture of bio-oil and chloroform) was collected and the biochar was dried in an oven for 12 hours at $105^{\circ} \mathrm{C}$. After drying, the biochar was stored in a ziplock bag. Only particles of a size less than $212 \mu \mathrm{m}$ were used in this study.

The discard Highveld coal filter cake (medium rank C bituminous coal) was reduced to less than $212 \mu \mathrm{m}$ using a ball mill. The proximate analysis results for the discard coal and biochar are given in Table I. It can be observed that the biochar has a very low ash content (5.2\%) compared with the discard coal (29\%), and the fixed carbon content is high (71.4\%) compared with the discard coal (41.5\%). 


\section{Green coal development for application in fixed-bed catalytic gasification}

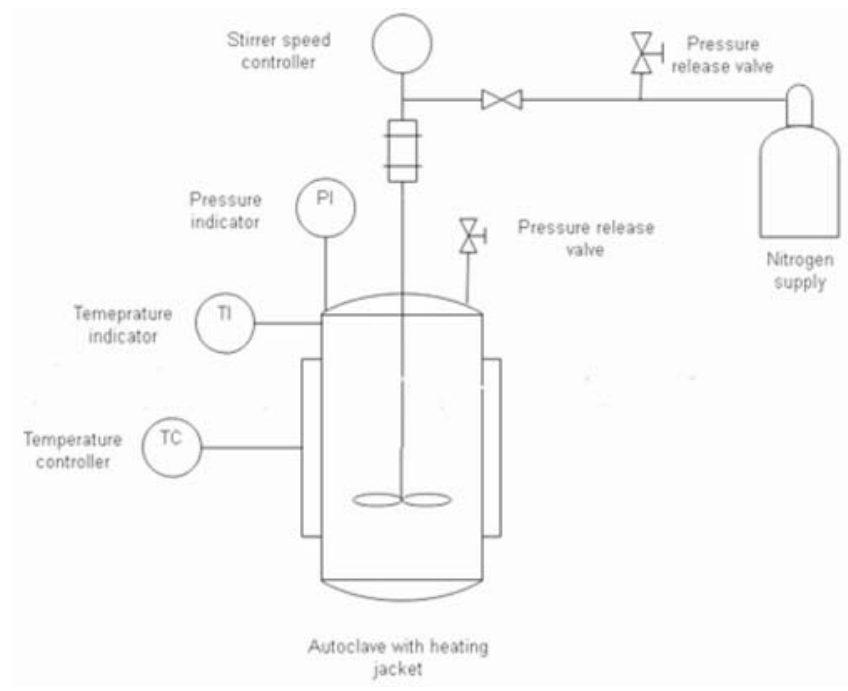

Figure 1-Schematic showing the autoclave set-up for the production of biochar

\section{Table I}

\section{Proximate analysis results (air-dried basis)}

\begin{tabular}{l|c|c}
\hline Procedure & Coal & Biochar \\
\hline Moisture content (wt\%) & 5.9 & 1.4 \\
\hline Ash content (wt\%) & 29.0 & 5.2 \\
\hline Volatile matter (wt\%) & 23.5 & 21.9 \\
\hline Fixed carbon (wt\%) & 41.5 & 71.4 \\
\hline
\end{tabular}

For the coal reactivity work, blend ratios of coal to biochar of $75: 25,50: 50$, and 25:75 were prepared by physical mixing. $\mathrm{CaCO}_{3}$ and $\mathrm{Ca}(\mathrm{OH})_{2}$ were used as catalysts and added to the $75: 25$ blend in $1 \mathrm{wt} \%, 3 \mathrm{wt} \%$, and $5 \mathrm{wt} \%$ concentrations. Pellets were pressed using an LRX Plus machine press operated with NEXYGEN PLUS software. The force of the machine was set at $4000 \mathrm{kN}$. Pellets $10 \mathrm{~mm}$ in diameter, 10 $\mathrm{mm}$ in height, and with a mass of $450 \mathrm{mg}$ were pressed. The samples were then gasified in a TGA with $\mathrm{CO}_{2}$ at temperatures of $900^{\circ} \mathrm{C}, 950^{\circ} \mathrm{C}$, and $1000^{\circ} \mathrm{C}$.

For the sulphur retention study, pellets were also pressed using the LRX machine press. Five different pellet types were pressed:

$>$ Coal pellets $(\mathrm{CC})$

> Biomass char pellets (BMC)

- A mixture of coal and biomass char pellets, containing a ratio of $70 \mathrm{wt} \%$ coal and $30 \mathrm{wt} \%$ biomass char (CC+BMC)

$>$ A mixture of coal and biomass char (70 wt $\%$ coal and 30 wt $\%$ biomass char) and $\mathrm{CaCO}_{3}$ as catalyst (CC+BMC+CAT1)

> A mixture of coal, biomass char (70 wt\% coal char and $30 \mathrm{wt} \%$ biomass char) and $\mathrm{Ca}(\mathrm{OH})_{2}$ as catalyst (CC+BMC+CAT2).

The catalyst addition was $3 \mathrm{wt} \%$ in all cases. The terms 'catalyst' and 'sorbent' are used interchangeably in this paper, as the same alkali metal acts as a catalyst during gasification before becoming deactivated at high temperatures, and in the case of combustion acts as a sorbent for in-situ sulphur capture. The samples were then reacted in air in a bayonettype glass reactor in a temperature range of $500^{\circ} \mathrm{C}$ to $800^{\circ} \mathrm{C}$, with continuous measurement of the $\mathrm{SO}_{2}$ gas concentration. A schematic of the experimental set-up is given in Figure 2.

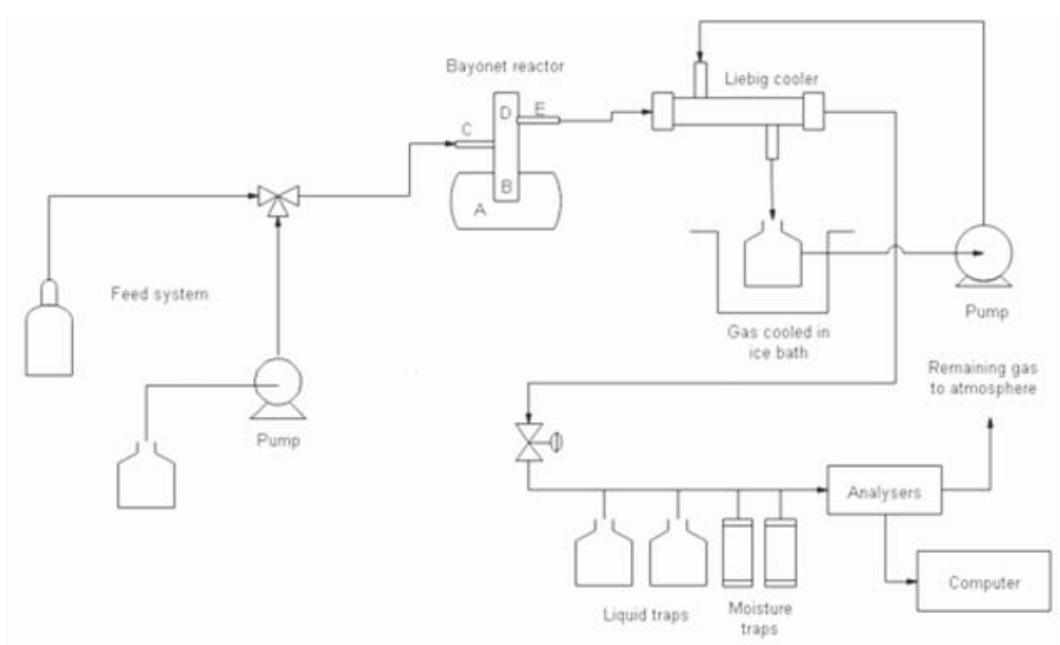

Figure 2-Schematic showing the experimental set-up of the combustion process used to measure retention of sulphur 


\section{Green coal development for application in fixed-bed catalytic gasification}

\section{TGA reactivity experiments}

The samples placed in the TGA were firstly heated to $30^{\circ} \mathrm{C}$ at a heating rate of $50^{\circ} \mathrm{C} / \mathrm{min}$ in a stream of $\mathrm{N}_{2}$ at a flow rate of $150 \mathrm{ml} / \mathrm{min}$. This temperature was held constant for 5 minutes. The samples were then pyrolised in an inert nitrogen atmosphere up to a final temperature of $1000^{\circ} \mathrm{C}$, using a TGA heating rate of $50^{\circ} \mathrm{C} / \mathrm{min}$ and streaming nitrogen at a flow rate of $150 \mathrm{ml} / \mathrm{min}$, and held at that temperature for 30 minutes. The gasification reactions were then carried out at $900^{\circ} \mathrm{C}, 950^{\circ} \mathrm{C}$, and $1000^{\circ} \mathrm{C}$ using carbon dioxide $\left(\mathrm{CO}_{2}\right)$ as reactant gas at a flow rate of $150 \mathrm{ml} / \mathrm{min}$. The reaction time was set to 6 hours.

\section{Sulphur retention experiments}

Figure 2 shows the experimental set-up of the combustion process used in order to measure retention of sulphur by the pellets. It should be noted that in a fixed- or moving-bed gasifier the reactant gases and solid fuel move countercurrent to one another. Essentially, oxygen combusts the char at the base of the gasifier, leading to the formation of $\mathrm{SO}_{2}$, which partitions to $\mathrm{H}_{2} \mathrm{~S}$ in the upper part of the gasifier where reducing conditions are prevalent and exits in this form in the raw syngas. The combustion reaction was studied as this reaction controls the formation of gaseous sulphur within the gasifier. The furnace of the reactor (A) was operated at temperatures between $500^{\circ} \mathrm{C}$ and $800^{\circ} \mathrm{C}$. The feed air entered the reactor at position (D) at a flow rate of $220 \mathrm{ml} / \mathrm{min}$. The pellets were inserted between two ceramic wool plugs at position B (glass reactor). A quartz sleeve (C) contained a thermocouple for continuous temperature measurements within the reaction zone. A PID controller was used to maintain a constant temperature. Position (E) indicates the effluent of the decomposed gases. The gas was then condensed in a Liebig cooler to slow down the flow rate before passing through liquid and moisture traps where all the remaining moisture was removed. The $\mathrm{SO}_{2}$ gas was then analysed by $\mathrm{a} \mathrm{SO}_{2}$ gas analyser before being vented to the atmosphere. $\mathrm{SO}_{2}$ gas is the only gas that can be detected by this analyser. To calibrate the $\mathrm{SO}_{2}$ reading, $1 \% \mathrm{SO}_{2}$ gas at a flow rate of $220 \mathrm{ml} / \mathrm{min}$ entered through the entire system until the reading reached equilibrium. The analyser was then spanned to zero, so that only the presence of $\mathrm{SO}_{2}$ produced by reaction could be detected when operating the combustion procedure, since the calibration gas addition was superfluous. Before starting the combustion process, all of the $\mathrm{SO}_{2}$ had to be removed from the system. Nitrogen gas at a high flow rate $(420 \mathrm{ml} / \mathrm{min}$ ) was passed through the system for about 20 minutes to purge all of the $\mathrm{SO}_{2}$ present. Once the $\mathrm{SO}_{2}$ gas analyser had been calibrated, the glass reactor was heated by the furnace to the desired temperature. Both the furnace and the glass reactor contained thermocouples for temperature control. When the desired temperature was reached, it was kept constant for the entire combustion process. Normally the glass reactor was approximately $20^{\circ} \mathrm{C}$ cooler than the furnace temperature. After the combustion process, the remaining ash residue of each sample was analysed. Inductively coupled plasma (ICP) analysis was conducted to investigate the concentrations of the elements in the sample, as well as to determine the sulphur retention.

\section{Modelling of sulphur transformational behaviour}

In order to demonstrate the gaseous sulphur reduction possible with the use of the green coal feedstock, a simulation of the fixed-bed gasification process was conducted to show the partitioning and speciation behaviour of the inorganic sulphur chemistry. The thermochemical simulation package used was FactSageTM 6.3, which is used extensively to study the high-temperature thermodynamic chemistry of inorganic minerals. The simulation input data was derived from the analysis (proximate, ultimate, elemental ash analysis) of a typical Highveld no. 4 seam coal from Secunda (Bunt et al., 2015).

The model input was as follows: carbon $(73.76 \mathrm{~g})$, nitrogen (1.99 g), oxygen (11.84 g), hydrogen (4.40 g), $\mathrm{Al}_{2} \mathrm{O}_{3}$ (2.05 g), $\mathrm{CaO}$ (0.93 g), $\mathrm{Cr}_{2} \mathrm{O}_{3}$ (0.01 g), $\mathrm{Fe}_{2} \mathrm{O}_{3}$ (0.78 g), $\mathrm{K}_{2} \mathrm{O}(0.05 \mathrm{~g}), \mathrm{MgO}(0.30 \mathrm{~g}), \mathrm{MnO}(0.009 \mathrm{~g}), \mathrm{Na}_{2} \mathrm{O}(0.05 \mathrm{~g})$, $\mathrm{SiO}_{2}$ (2.91 g), $\mathrm{TiO}_{2}(0.14 \mathrm{~g}), \mathrm{V}_{2} \mathrm{O}_{5}$ (0.006 g), $\mathrm{ZrO}_{2}$ (0.01 g), $\mathrm{Ba}(0.04 \mathrm{~g})$. Sulphur was introduced as $\mathrm{FeS}_{2}(1 \%)$. To

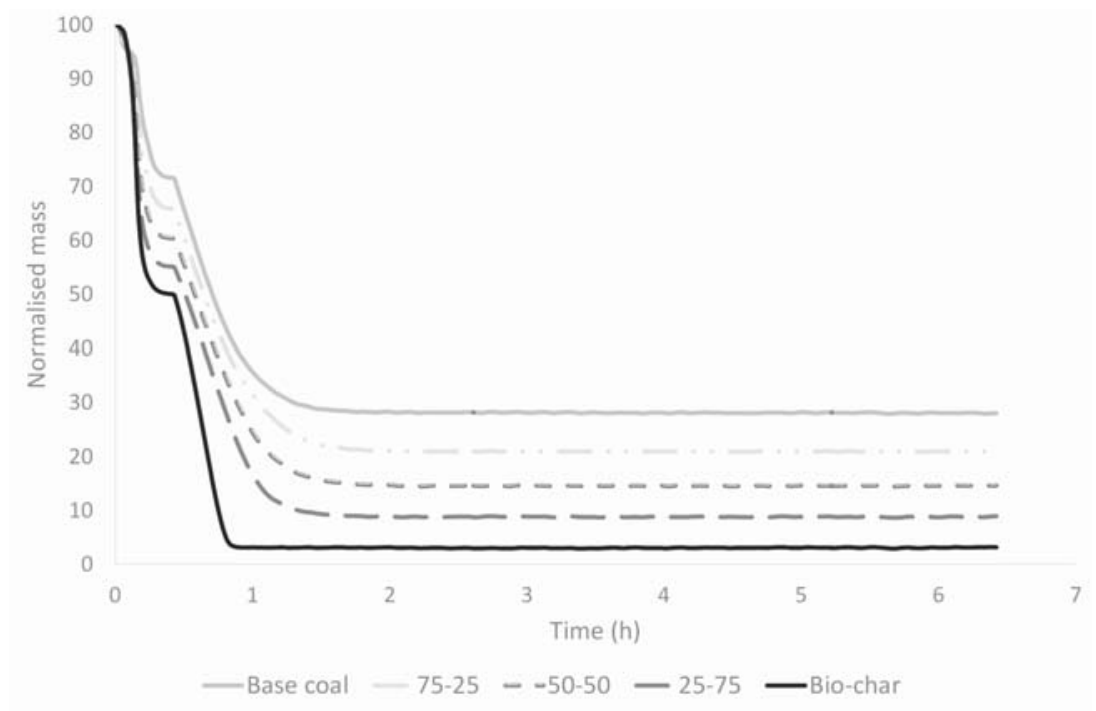

Figure 3-Normalized mass loss curves of base coal, biochar, and blends at $1000^{\circ} \mathrm{C}$ 


\section{Green coal development for application in fixed-bed catalytic gasification}

simulate the gasification process, hydrogen gas was introduced in excess $(100 \mathrm{~g})$ in order to ensure that the chemical system was under strictly reducing conditions. In practice, hydrogen will be produced from the steam gasification reaction together with char. Hydrogen is produced in the reduction zone of the fixed-bed gasifier and its reaction with $\mathrm{S}$ species $\left(\mathrm{FeS}_{2}\right.$ and $\left.\mathrm{FeS}\right)$ as it moves upwards through the char/coal bed needs to be understood, both in the absence and the presence of an alkali metal sorbent. Dolomite [ $\left.\mathrm{Ca} / \mathrm{Mg}\left(\mathrm{CO}_{3}\right)_{2}\right](10 \mathrm{~g})$ was added to the system to investigate the possibility of sulphur capturing and retention, and the results were compared to a base case simulation with no dolomite present. Since catalytic gasification is proposed to operate at temperatures of $1000^{\circ} \mathrm{C}$ (max.), the simulation considered the temperature range $25^{\circ} \mathrm{C}$ to $1025^{\circ} \mathrm{C}$, in steps of $100^{\circ} \mathrm{C}$. The gasifier pressure was fixed at 28 bar, which is typical of this technology, as also used by Sasol (Bunt and Waanders, 2008). The FactSageTM distribution function was used to disseminate the sulphur species behaviour once the simulation was completed.

\section{Results and discussion}

\section{TGA reactivity}

Figure 3 shows the normalized mass loss curves for the base coal, biochar, and the various coal and biochar blends at $1000^{\circ} \mathrm{C}$. It can be seen that the ash content of the individual blends decreases as the biochar loading increases. It is clear that the mass loss of biochar is much faster than that of coal.

To calculate the reaction rate, the moisture content, volatile matter, and ash content were removed from the mass loss curve to obtain the carbon mass loss curve. The reaction rate was calculated using Equation [1]:

$$
r=\frac{d m}{d t} \frac{1}{m_{t}}
$$

The carbon conversion was calculated using Equation [2]:

$$
x=\frac{m_{i}-m_{t}}{m_{i}-m_{\text {ash }}}
$$

where $m_{\text {ash }}$ is the mass of the ash in the respective samples.
Figure 4 shows the reaction rates (g/g.h-1) of base coal, biochar, and the various blends at $1000^{\circ} \mathrm{C}$. It is apparent that the reaction rate of biochar is much higher than that of the base coal and the individual blends. The high reaction rate of biochar is a well-known phenomenon and has been studied extensively (Brown, Liu, and Norton, 2000; Emami-Taba et al., 2013; Jeong, Park, and Hwang, 2014). The high reaction rate can be attributed to the high alkali metal content of biochar and weak bonds between holocellulose and lignin (Emami-Taba et al., 2013).

Although the reaction rates of the base coal and individual blends are quite similar at the start of gasification, the reaction rate of the $25: 75$ blend increases significantly at a conversion of $70 \%$, and becomes faster than that of the base coal, the $50: 50$ blend, and the $75: 25$ blend. It can be seen that the $75: 25$ blend has the lowest reaction rate at the end of the reaction. At a temperature of $900^{\circ} \mathrm{C}$ (not shown here), the differences in the reaction rates were more pronounced, suggesting that the catalytic effect is greater at lower temperatures.

To determine if reaction inhibition is present, the theoretical conversion was calculated using the method proposed by Ren et al., (2011) (Equation [3]) and compared to the experimental values.

$$
\begin{aligned}
X_{\text {calculated }} & =\frac{\left(m_{i, \text { coal }}-m_{f, \text { coal }}\right) X_{\text {coal }}}{\left(m_{i, \text { coal }}-m_{f, \text { coal }}\right.} \\
& \frac{+\left(m_{i, \text { bio-char }}-m_{f, \text { bio-char }}\right) X_{\text {bio }- \text { char }}}{+\left(m_{i, \text { bio }- \text { char }}-m_{f, \text { bio }} \text { char }\right)}
\end{aligned}
$$

where $X_{\text {calculated }}$ is the conversion at time $t$ of the base-case run. If $X_{\text {calculated }}$ is larger than the experimental conversion for any blend, reaction inhibition is suspected. If $X_{\text {calculated }}$ is smaller than the experimental conversion, synergistic effects are present. Figures 5 and 6 show some sample results obtained. It can be seen that the theoretical conversion is higher than almost all of the experimental conversions, indicating that reaction inhibition is taking place. Only the $25: 75$ blend at $900^{\circ} \mathrm{C}$ (Figure 6) shows synergistic effects, which once again indicates that a lower temperature might be beneficial to the co-gasification reactions.
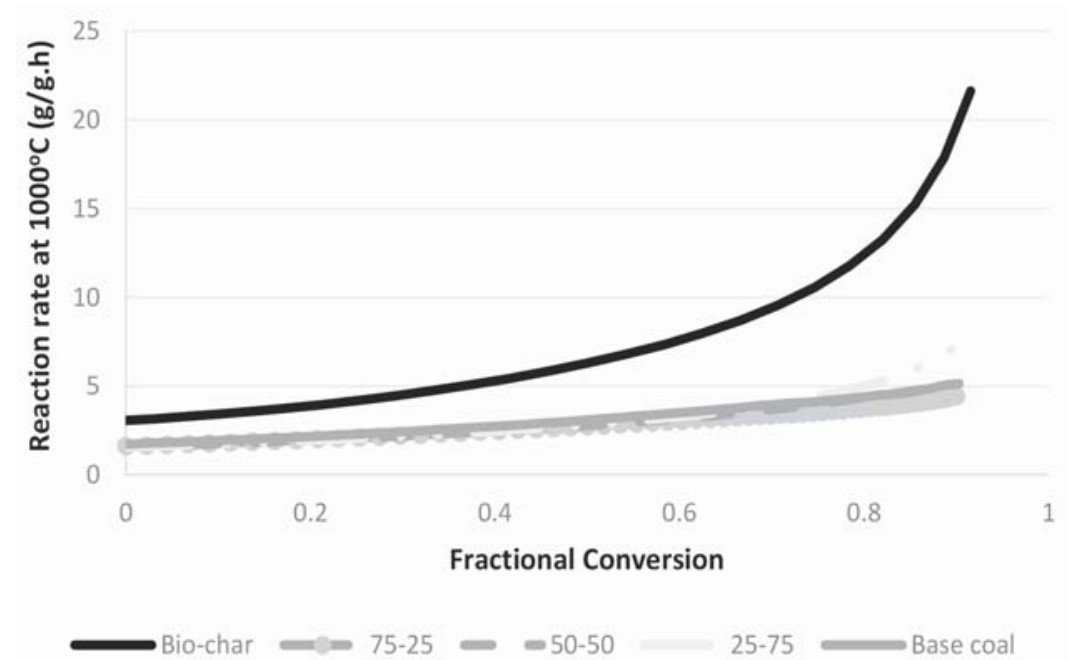


\section{Green coal development for application in fixed-bed catalytic gasification}

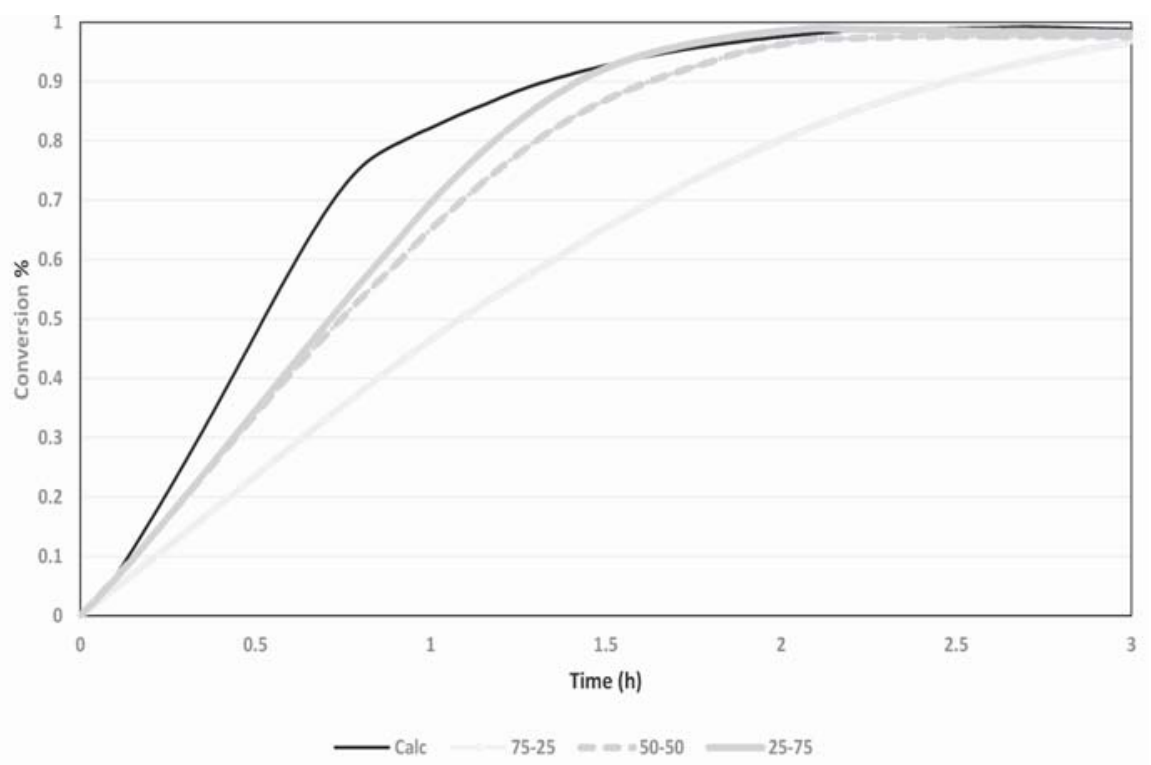

Figure 5-Theoretical and experimental conversions obtained at $950^{\circ} \mathrm{C}$

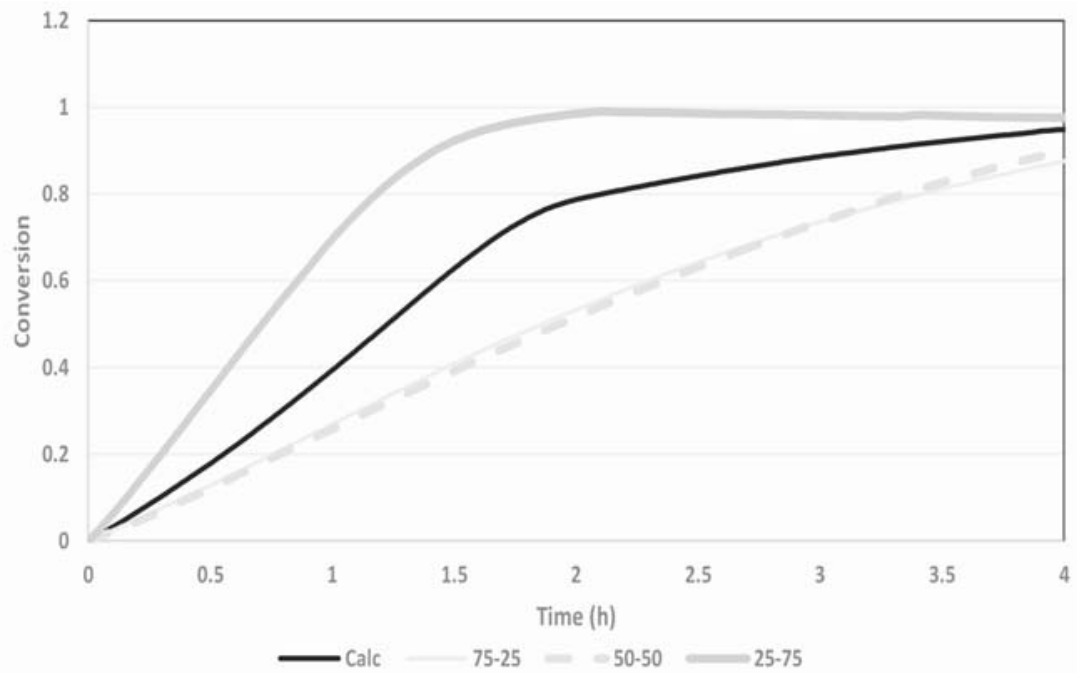

Figure 6-Theoretical and experimental conversions obtained at $900^{\circ} \mathrm{C}$

A number of studies have been conducted to understand the interaction between coal and biochar and to explain the reaction inhibition. Habibi (2013) studied the co-gasification of switchgrass with coal and fluid coke. It was found that inhibition occurs in the co-gasification of switchgrass and coal, which was attributed to alkali metals reacting with aluminosilicates to form immobile compounds such as $\mathrm{KAlSi}_{3} \mathrm{O}_{8}$ and $\mathrm{KAlSiO}_{4}$. However, synergistic effects were observed between switchgrass and fluid coke, considering the fluid coke contained less mineral matter than coal. Ren et al., (2011) co-gasified bone meal and coal and found that at higher temperatures, $\mathrm{Ca}$ and $\mathrm{Na}$ reacted with mineral matter to form alkali aluminosilicates, thus also inhibiting the reaction. The same inhibiting effect was possibly observed in this study, and is likely caused by the formation of alkali aluminosilicates.

To determine the effect of catalyst addition on the reaction rate of coal and biochar blends, $\mathrm{CaCO}_{3}$ was added to the $75: 25$ blend in $1 \mathrm{wt} \%$, $3 \mathrm{wt} \%$, and $5 \mathrm{wt} \%$ concentrations.
Figure 7 shows the effect of $\mathrm{CaCO}_{3}$ on the reaction rate at $1000^{\circ} \mathrm{C}$. It can be seen that the addition of $\mathrm{CaCO}_{3}$ as catalyst increases the reaction rate of the 75:25 blend. The blend containing $1 \mathrm{wt} \% \mathrm{CaCO}_{3}$ shows the smallest increase in the reaction rate, while the $3 \mathrm{wt} \%$ addition shows the highest increase. Some inhibition is observed when $5 \mathrm{wt} \% \mathrm{CaCO}_{3}$ is added, considering the reaction rate is slower than that of the $3 \mathrm{wt} \%$ sample. The optimal catalyst addition seems to be 3 $\mathrm{wt} \%$. It is known that the mobility of alkali metal salts under gasification operating conditions should lead to good dispersion throughout the coal surface, resulting in an enhanced reaction rate. However, if the salt is present in excess, it can also react with aluminosilcates to form inactive alkali aluminosilicates, resulting in an observed inhibition in reaction rate, as is postulated in this study.

The observed activation energy and pre-exponential factor of the Arrhenius equation were calculated by linearization of the Arrhenius equation, as shown in Equation [4]: 


\section{Green coal development for application in fixed-bed catalytic gasification}

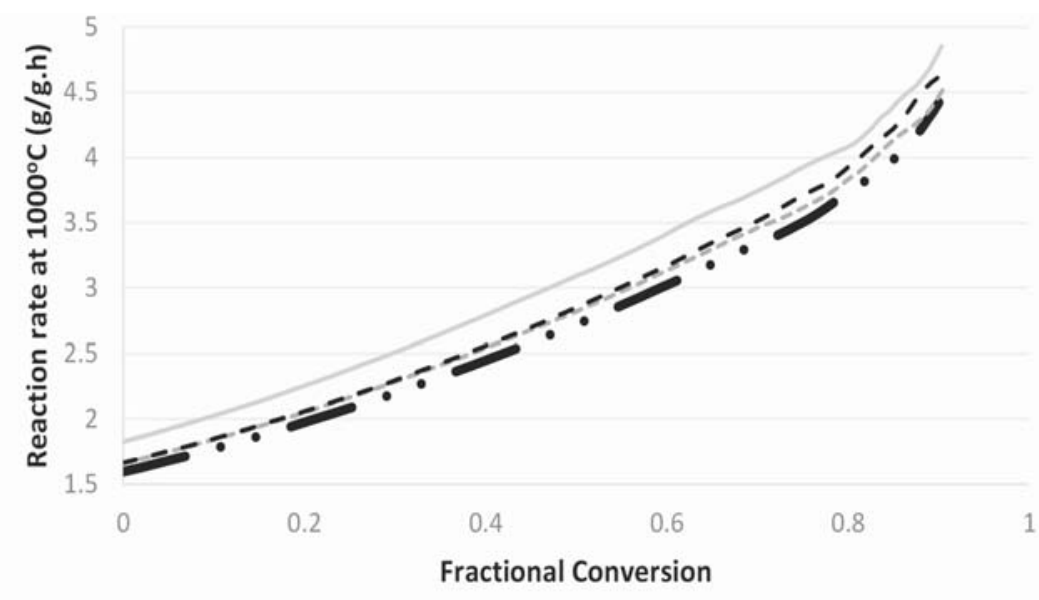

-75-25 -- $75-25+1 \%$ cat $\longrightarrow$ 75-25+3\% cat - - $-75-25+5 \%$ cat

Figure 7-Effect of $\mathrm{CaCO}_{3}$ addition on the reaction rate of the $75: 25$ blend at $1000^{\circ} \mathrm{C}$

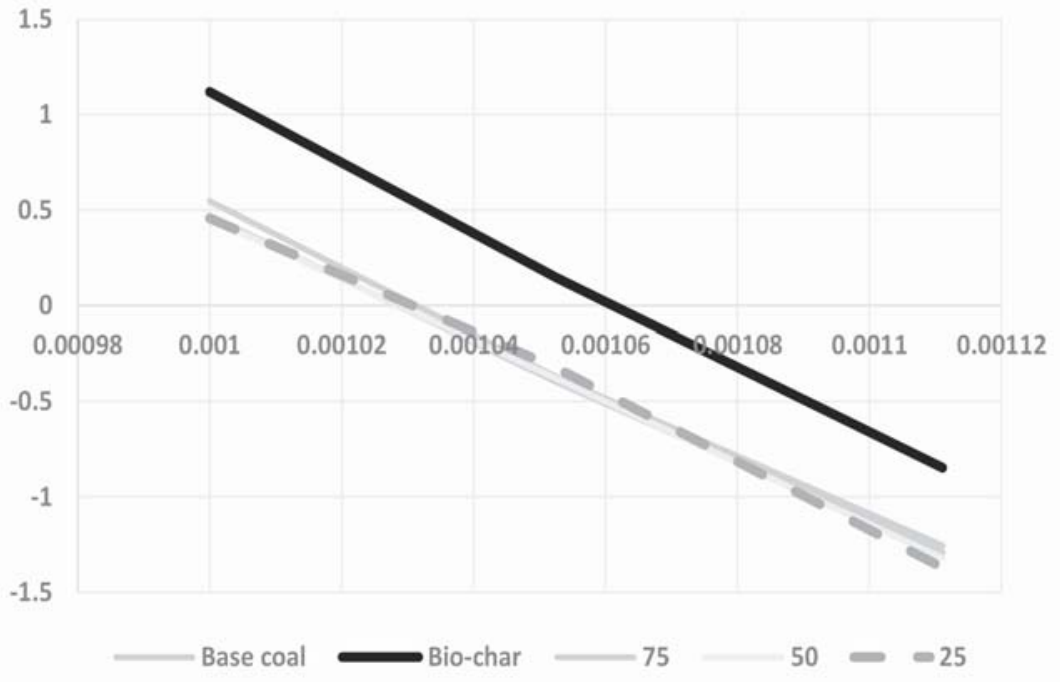

Figure 8-Arrhenius plots for the base coal, biochar. and respective blends

$$
\operatorname{In} r=\operatorname{In} A-\frac{E}{R}\left(\frac{1}{T}\right)
$$

By plotting $\ln r$ versus $\frac{1}{T}$, the linearized Arrhenius plots were obtained. Figure 8 shows the Arrhenius plots for the base coal, biochar, and respective blends.

From the kinetic data is it clear that biochar had a much higher reaction rate than the base coal. As the biochar loading increased, the reaction rate also increased. However, some reaction inhibition was observed, which could be attributed to the formation of inactive alkali aluminosilicates. The increase in the reaction rate was more pronounced as the temperature decreased.

The activation energies of coal and biochar were found to be $224 \mathrm{~kJ} / \mathrm{mol}$ and $242 \mathrm{~kJ} / \mathrm{mol}$, respectively. Furthermore, the activation energies of the $75: 25,50: 50$, and 25:75 blends were found to be $219 \mathrm{~kJ} / \mathrm{mol}, 221 \mathrm{~kJ} / \mathrm{mol}$, and $227 \mathrm{~kJ} / \mathrm{mol}$, respectively. The activation energies of the blends containing
$1 \mathrm{wt} \%, 3 \mathrm{wt} \%$ and $5 \mathrm{wt} \% \mathrm{CaCO}_{3}$ were $222 \mathrm{~kJ} / \mathrm{mol}, 233$ $\mathrm{kJ} / \mathrm{mol}$, and $222 \mathrm{~kJ} / \mathrm{mol}$, respectively.

The homogeneous model, shrinking core model, and Wen's model (not shown here) were all capable of predicting the conversion accurately, considering that no $\mathrm{R}^{2}$ value was found to be lower than 0.94 .

\section{Sulphur retention}

Figure 9 shows the results obtained during the combustion of biomass char pellets $(\mathrm{BMC})$ at $700^{\circ} \mathrm{C}$. Each run consisted of $920 \mathrm{mg} \mathrm{BMC}$ and a total of five runs were conducted in order to obtain effective repeatability results. The average, minimum, and maximum data for the five runs were plotted. The average curve was determined by taking the average data for all five runs. The average maximum peak for $\mathrm{SO}_{2}$ emissions was 3400 ppm, which was reached in the first 220 seconds. Each combustion test was completed in approximately 30 minutes. 


\section{Green coal development for application in fixed-bed catalytic gasification}

The $\mathrm{SO}_{2}$ reduction emission efficiencies for the combustion runs conducted at temperatures ranging from $500-800^{\circ} \mathrm{C}$ were calculated using Equation [5]

$S=1-\frac{(\text { Sulphur before combustion }- \text { Sulphur after combustion }(\mathrm{mg}))}{\text { Sulphur before combustion }(\mathrm{mg})}[5]$

The sulphur before combustion was calculated using the sulphur percentage obtained from the ultimate analysis multiplied by the total mass. The total sulphur after combustion was calculated using the sulphur wt $\%$ obtained from the ICP analysis multiplied by the total ash wt\%. Table II shows the sulphur retention results obtained for the various samples with respect to combustion temperature.

It can be observed that in the case of the BMC pellets the sulphur retention ranged between $13 \%$ and $18 \%$ within the temperature range studied. For the coal (CC) pellets, sulphur retention ranged between $16 \%$ and $34 \%$; decreasing with

Table II

Sulphur retention as function of reaction temperature for the five cases studied

\begin{tabular}{|l|c|c|c|c|}
\hline Type & $\begin{array}{c}\% \text { S retention } \\
(\mathbf{5 0 0} \mathbf{C})\end{array}$ & $\begin{array}{c}\% \text { S retention } \\
(\mathbf{6 0 0} \mathbf{C})\end{array}$ & $\begin{array}{c}\% \text { S retention } \\
(\mathbf{7 0 0} \mathbf{C})\end{array}$ & $\begin{array}{c}\% \text { S retention } \\
\left(\mathbf{8 0 0} 0^{\circ} \mathbf{C}\right)\end{array}$ \\
\hline BMC & 18 & 13 & 15 & 14 \\
\hline $\mathrm{CC}$ & 34 & 22 & 17 & 16 \\
\hline BMC+CC (30:70) & 29 & 19 & 16 & 15 \\
\hline BMC+CC+CAT1 & 60 & 78 & 52 & 39 \\
\hline BMC+CC+CAT2 & 86 & 74 & 67 & 56 \\
\hline
\end{tabular}

increasing temperature. In the case of the mixture of $\mathrm{CC}+\mathrm{BMC}$ pellets, the sulphur retention ranged between 15\% and $29 \%$. When the catalyst/sorbent was added $(\mathrm{CC}+\mathrm{BMC}+\mathrm{CAT} 1)$, the sulphur retention increased significantly to between $39 \%$ and $78 \%$.

Finally, when $(\mathrm{CC}+\mathrm{BMC}+\mathrm{CAT} 2)$ was combusted, the sulphur retention was found to range between $56 \%$ and $86 \%$ for the four temperatures studied. There is thus clear evidence that $5 \%$ sorbent addition effectively increased the sulphur retention during the combustion experiments. The $\mathrm{Ca}(\mathrm{OH})_{2}$ catalyst is the more effective catalyst/sorbent compared to $\mathrm{CaCO}_{3}$. The most effective pellet for retaining elemental sulphur was found to be the (biomass char, coal, and $\mathrm{Ca}(\mathrm{OH})_{2}$ ) pellet, with the highest sulphur retention of $86 \%$ at $500^{\circ} \mathrm{C}$. The addition of a catalyst/sorbent, especially $\mathrm{Ca}(\mathrm{OH})_{2}$, tends to minimize the effect of temperature change on the combustion process and also stabilizes the $\mathrm{SO}_{2}$ emission curves. Without the addition of a sorbent, the biomass char and coal pellet mixture was found to be the most efficient, with a sulphur retention efficiency of only $29 \%$ at $500^{\circ} \mathrm{C}$. This retention was caused by the reactive alkali metals in the natural ash-forming minerals present in the coal pellet mixture.

In the case of catalytic gasification (where oxidizing and reducing conditions are present in the bottom and top halves of the gasifier, respectively), the operating temperature should preferably not exceed $1000^{\circ} \mathrm{C}$ in the combustion zone. It can be concluded from this example that a sulphur retention of close to $60 \%$ is obtained at a temperature of $800^{\circ} \mathrm{C}$. It was also shown earlier that the $\mathrm{CO}_{2}$ reaction rate (reactivity) is highest at lower operating temperature. Thus, it has been proven experimentally that the $\mathrm{BM}+\mathrm{CC}+\mathrm{CAT}(1 / 2)$ formulation is capable of both (1) enhancing reaction rate

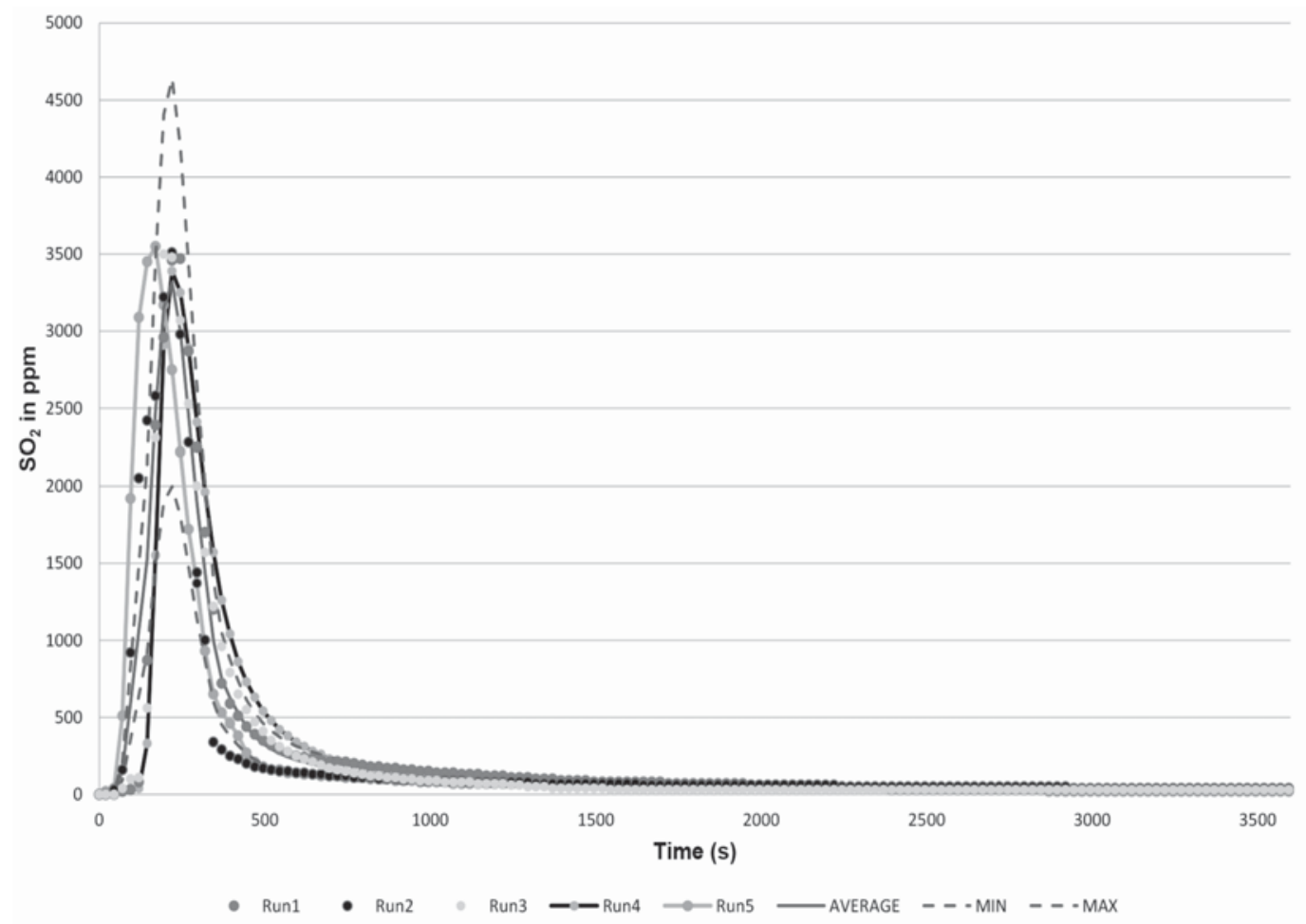

Figure $9-\mathrm{SO}_{2}$ results obtained during the combustion of biomass char pellets (BMC) at $700^{\circ} \mathrm{C}$ 


\section{Green coal development for application in fixed-bed catalytic gasification}

during $\mathrm{CO}_{2}$ gasification, as well as (2) significantly retaining sulphur in the ash during combustion, and an international patent has been granted (Waanders, Marx, and Bunt, 2016).

The co-utilization of carbon feedstocks, particularly those of a biomass origin, is considered to deliver lower net $\mathrm{CO}_{2}$ generation, as biomass is deemed to be renewable and produces less $\mathrm{CO}_{2}$ emissions than coal, because biomass is suggested to be $\mathrm{CO}_{2}$-neutral with regard to the greenhouse gas balance. In most cases the bio-oil will be used as binder if briquetting together with fine coal is being considered. In the case of green coal, the bio-residue is utilized as a carbon source together with fine discard coal. The biochar prepared at a temperature of approximately $300^{\circ} \mathrm{C}$ is similar to young lignite in terms of coal rank, and is therefore considered a highly reactive carbon source.

\section{Sulphur modelling}

Figure 10 shows the base case model output results (reaction temperature versus sulphur species fractional \% distribution).
It can be observed that in this highly reducing atmosphere, pyrite decomposes at $125^{\circ} \mathrm{C}$ forming pyrrhotite (FeS) with the release of $\mathrm{H}_{2} \mathrm{~S}$ gas according to the reaction $\mathrm{FeS}_{2}+\mathrm{H}_{2} \rightarrow$ $\mathrm{Fe}_{(1-\mathrm{x})} \mathrm{S}+\mathrm{H}_{2} \mathrm{~S}$. FeS is stable up to a temperature of $525^{\circ} \mathrm{C}$, whereafter it decomposes, and is not present above $725^{\circ} \mathrm{C}$. At this point, all of the sulphur (in the form of $\mathrm{H}_{2} \mathrm{~S}$ ) is present in the gas phase, in agreement with the literature (Skhonde et al., 2009).

Figure 11 shows the simulation output for the dolomiteadded scenario under reducing conditions. It can be observed that the speciation of $\mathrm{FeS}_{2}$ and FeS occurs in an identical fashion as in the base-case run, but the formation of a calcium sulphide (CaS) solid species is now also evident. According to Abbasain et al., (1990), this species starts forming in the process, and the primary sulphidation reactions take place within the gasifier under reducing conditions. The limestone is calcined at gasification conditions, and sulphur capture occurs through the reaction of calcium oxide with hydrogen sulphide as shown in Equations [6] and [7] respectively:

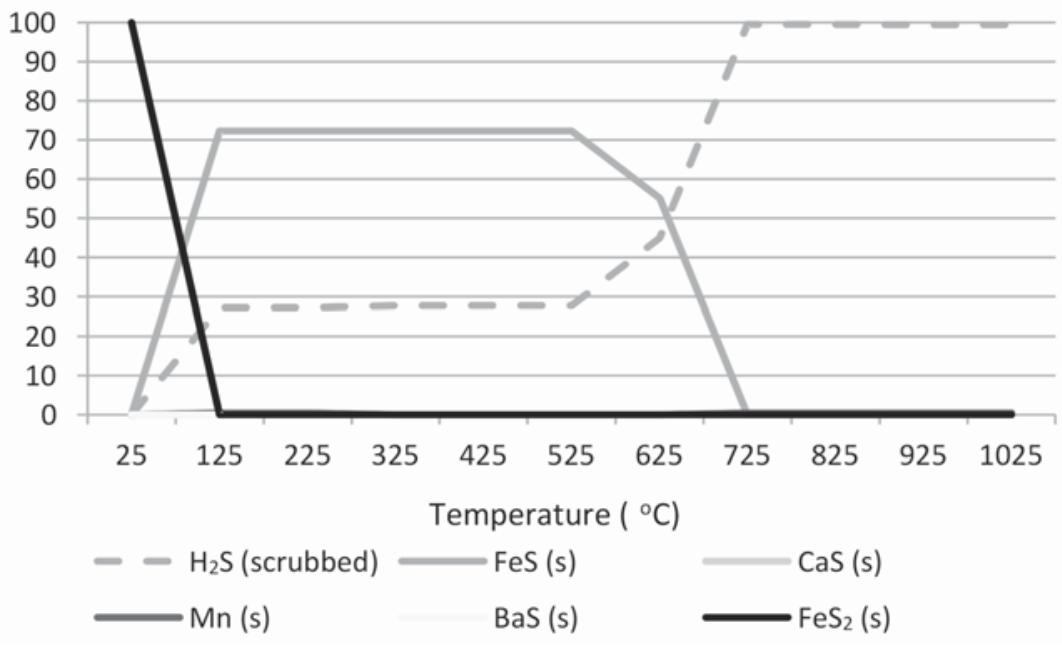

Figure 10-Fixed-bed gasifier simulation showing the speciation behaviour of sulphur in a reducing environment $\left(25-1025^{\circ} \mathrm{C}\right)$

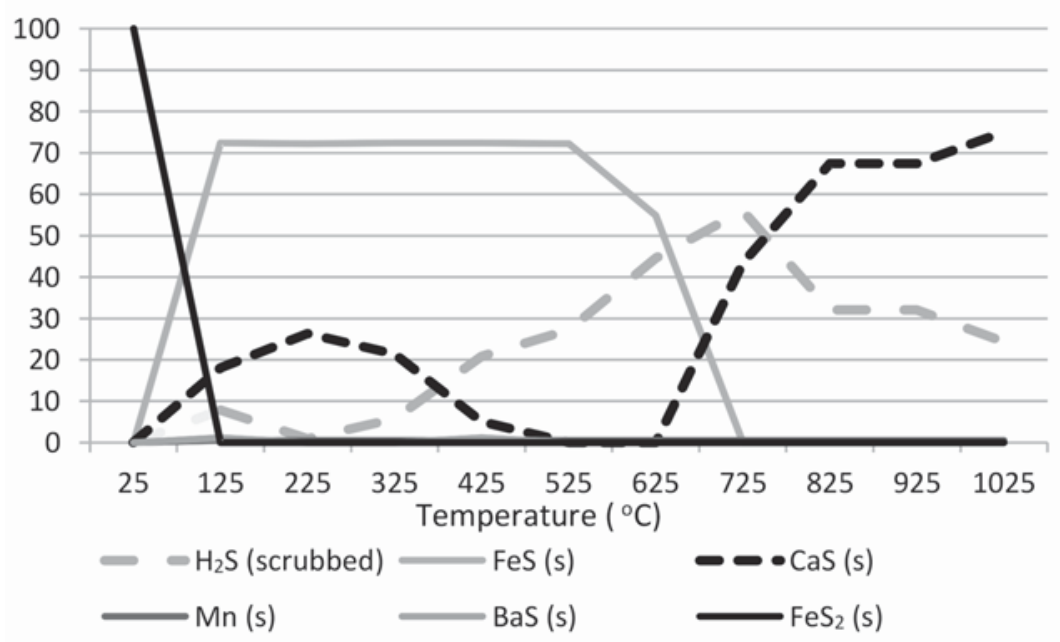

Figure 11-Fixed-bed gasifier simulation showing the speciation behaviour of sulphur in a reducing environment (25-1025oC) in the presence of dolomite 


\section{Green coal development for application in fixed-bed catalytic gasification}

$$
\begin{aligned}
& \mathrm{CaCO}_{3} / \mathrm{MgCO}_{3} \rightarrow \mathrm{CaO} / \mathrm{MgO}+2 \mathrm{CO}_{2} \\
& \mathrm{CaO} / \mathrm{MgO}+\mathrm{H}_{2} \mathrm{~S} \rightarrow \mathrm{CaS}+\mathrm{MgO}+\mathrm{H}_{2} \mathrm{O}
\end{aligned}
$$

The simulation in Figure 11 shows that a CaS (s1) phase is possible at temperatures ranging between $125^{\circ} \mathrm{C}$ and $425^{\circ} \mathrm{C}$. When the FeS solid species has finally decomposed and the dolomite has been calcined at $625^{\circ} \mathrm{C}$ (Equation [6]), a CaS (s2) transition state product is formed (Equation [7]), and a clear reduction in gaseous $\mathrm{H}_{2} \mathrm{~S}$ is evident. At $1025^{\circ} \mathrm{C}$, the fractional $\mathrm{H}_{2} \mathrm{~S}$ distribution has been reduced to $24 \%$, with the CaS (solid reaction product) accounting for the remaining $76 \%$. This result is in fair agreement with results reported by Abbasin et al., (1990), who claimed a 90\% removal of sulphur in the form of $\mathrm{CaS}$ during fluidized-bed gasification studies.

However, the CaS product formed under reducing conditions (as shown by the simulation) is water-soluble and cannot therefore be disposed of in the ash product exiting the gasifier. It is known that $\mathrm{CaS}$ reacts with water to form $\mathrm{H}_{2} \mathrm{~S}$ in solution and $\mathrm{Ca}(\mathrm{OH})_{2}$ (Waanders, Marx, and Bunt, (2016). Fortunately, oxidizing conditions are also needed during the fixed-bed gasification process, and Figure 12 shows the simulation result when the $\mathrm{CaS}$ and $\mathrm{H}_{2} \mathrm{~S}$ products formed are reacted with oxygen. The input data for this simulation was taken as the model output as given at a temperature of $825^{\circ} \mathrm{C}$, because the catalytic gasification process needs to run at temperatures below $1000^{\circ} \mathrm{C}$. In this case, the $\mathrm{CaS}$ and $\mathrm{H}_{2} \mathrm{~S}$ distributions were approximately $70 \%$ and $30 \%$ respectively. The simulation input data was as follows: $\mathrm{H}_{2} \mathrm{~S}(0.85 \mathrm{~g}), \mathrm{H}_{2}$ $(0.10 \mathrm{~g}), \mathrm{Mg}_{2} \mathrm{Al}_{4} \mathrm{Si}_{5} \mathrm{O}_{18}$ - corderite $(4.59 \mathrm{~g})$, CaS $(3.15 \mathrm{~g})$, $\mathrm{MgS}(1.07 \mathrm{~g}), \mathrm{NaAlSi}_{2} \mathrm{O}_{8}$ - high-albite $(0.44 \mathrm{~g}), \mathrm{Al}_{6} \mathrm{Si}_{2} \mathrm{O}_{13}-$ mullite $(0.43 \mathrm{~g})$, $\mathrm{KAlSi}_{2} \mathrm{O}_{6}$ - leucite $(0.24 \mathrm{~g})$, and $\mathrm{TiS}_{2}(0.20$ g). An assumption was made to include carbon $(10 \mathrm{~g})$ since the thermodynamic model takes the process to complete equilibrium, yet it is known in practice that between 10 and
$20 \%$ of the carbonaceous char is finally combusted during fixed-bed gasification (Bunt and Waanders, 2008). An excess of oxygen $(50 \mathrm{~g})$ was added to the model input to simulate the effect of oxidation of the CaS species, in particular.

Figure 12 clearly shows the effect of sulphur capturing during the oxidation step; i.e. the CaS is oxidized to insoluble $\mathrm{CaSO}_{4}(40 \%)$ and corderite reacts with oxygen and sulphur to form $\mathrm{MgSO}_{4}(13 \%)$ at $925^{\circ} \mathrm{C}$. As expected, the gaseous products formed are $\mathrm{SO}_{2}$ and $\mathrm{SO}_{3}\left(47 \%\right.$ in total at $\left.925^{\circ} \mathrm{C}\right)$. The $\mathrm{CaSO}_{4}$ distribution remains constant at higher temperatures up to $1225^{\circ} \mathrm{C}$ according to the reaction $\mathrm{CaS}+$ $2 \mathrm{O}_{2} \rightarrow \mathrm{CaSO}_{4}$. The gaseous products of oxidation $\left(\mathrm{SO}_{2}, \mathrm{SO}_{3}\right)$ will further react with hydrogen under reducing conditions higher up in the fixed-bed gasifier to form $\mathrm{H}_{2} \mathrm{~S}$, and be released into the raw syngas as this species. On the other hand, the $\mathrm{CaSO}_{4}$ species formed in the bottom of the gasifier will exit the reactor as part of the solid ash assemblage.

This simulated example has shown that $53 \%$ of the pyritic sulphur entering the fixed-bed gasifier is removed from the gaseous phase as insoluble $\mathrm{CaSO}_{4}$ during operation in a catalytic gasification mode.

\section{Concluding remarks}

Minimizing the amount of sulphur partitioning to the gas phase during utilization lowers the total cost of the gas cleanup process. 'Green coal' has the potential to reduce the current gaseous sulphur emissions during fixed-bed gasification by up to $50 \%$, with the balance of the sulphur encapsulated in an insoluble solid phase in the ash assemblage.

With the green coal formulation, the catalyst plays a dual role: (1) self-scrubbing (in-situ capture) of sulphur during utilization in fixed-bed gasification or any process operating on lump coal, as well as (2) enhancing the rate-limiting $\mathrm{CO}_{2}$ gasification step of the char. Green coal thus has the capability of at least doubling the gasification reactivity, thus allowing for enhanced throughput possibilities in fixed-bed gasifiers.

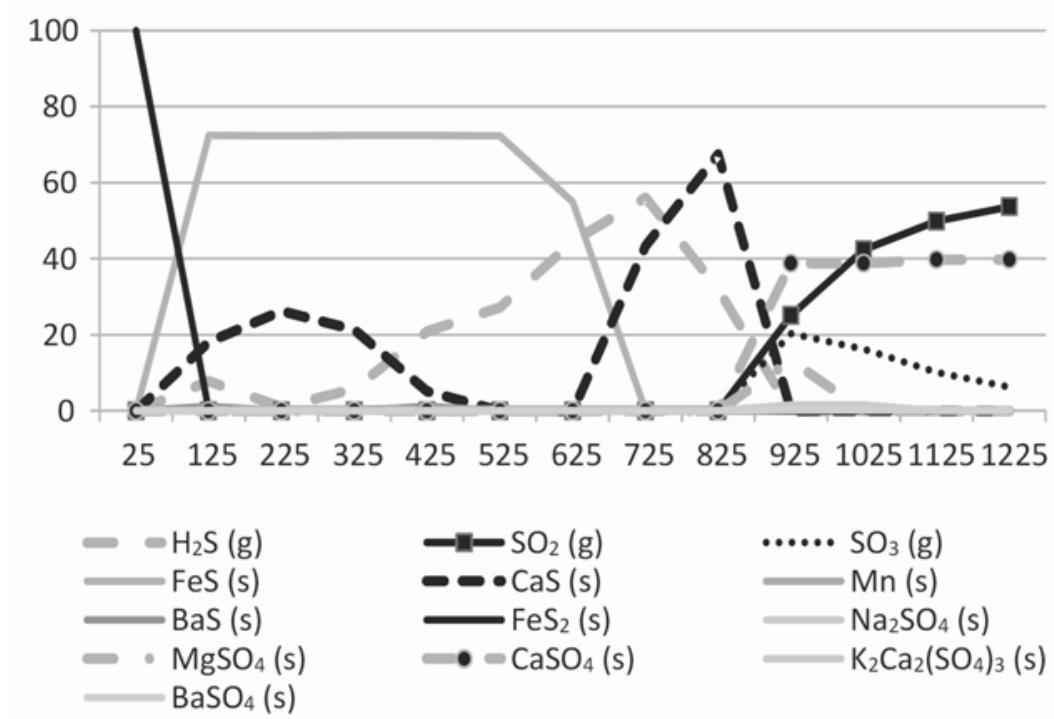

Figure 12-Fixed-bed gasifier simulation showing the speciation behaviour of sulphur in a reducing and oxidizing environment in the presence of dolomite $\left(25-1225^{\circ} \mathrm{C}\right)$ 


\section{Green coal development for application in fixed-bed catalytic gasification}

The use of green coal essentially offers an attractive solution since it is formulated from a combination of discard fine coal and biochar (a carbonaceous residue after bio-oil extraction). The biochar addition to the formulation is considered a renewable energy source, thus carbon credits can be claimed due to the reduction in $\mathrm{CO}_{2}$ production.

\section{Acknowledgements}

The research was conducted in affiliation with TIA and the Coal Research Group, Unit of Energy Systems, of the School for Chemical and Minerals Engineering of the North-West University, which is acknowledged for funding and valuable assistance. The work presented in this paper is based on research supported by the South African Research Chairs Initiative of the Department of Science and Technology and National Research Foundation (NRF) of South Africa (Chair Grant numbers 86880, UID85643, and UID85632). Any opinion, finding, or conclusion or recommendation expressed in this material is that of the authors and the NRF does not accept any liability in this regard.

\section{References}

Abbasian, M.J., Rehmat, A., LepPin, D., and BAnerJeE, D. 1990. Desulfurization of fuel gas with calcium-based sorbents. Fuel Processing Technoogy, vol. 25. pp. 1-10.

Biagini, E., Lippi, F., Petarca, L., and TognotTi, L. 2002. Devolatilisation rate of biomasses and coal-biomass blends; an experimental investigation. Fuel, vol. 81. pp.1041-1050.

BORGWARDT, R.H. and ROACHE, N.F. 1984. Reaction of $\mathrm{H}_{2} \mathrm{~S}$ and sulfur with limestone particles. Industrial \& Engineering Chemistry Process Design and Development, vol. 23, no. 4. pp. 742-748. doi: 10.1021/i200027a020

BORGWARDT, RH., ROACHE, N.F., and BRUCE, K.R. 1984. Surface area of calcium oxide and kinetics of calcium-sulfide formation. Environmental Progress, vol. 2, no. 2. doi: 10.1002/ep.670030215

Bridgman, T.G., Jone, J.M., Shield, I., and Williams, P.J. 2008. Torrefaction of reed canary grass, wheat straw and willow to enhance solid fuel quantities and combustion properties. Fuel, vol. 87. pp. 844-856.

Brown, R.C., Liu, Q., and Norton, G. 2000. Catalytic effects observed during the co-gasification of coal and switchgrass. Biomass and Bioenergy, vol. 18. pp. 499-506.

BunT, J.R. and vAN NiERoP, P. 1997. Development of a fine coal circuit for Sasol's Twistdraai Colliery. Proceedings of the 13th Annual International Pittsburgh Coal Conference and Workshop, Shanxi, China, August 1997.

BunT, J.R. and WAANDERS, F.B. 2008. An understanding of the behaviour of a number of element phases impacting on a commercial-scale Sasol-Lurgi FBDB gasifier. Fuel, vol. 87. pp. 1751-1762.

Bunt, J.R., Neomagus, H.W.J.P, BothA, A.A., and WaAnders, F.B. 2015. Reactivity study of fine coal agglomerates. Journal of Analytical and Applied Pyrolysis, vol. 113. pp. 723-728.

CHAng, E. and Thodos, G. 1984. Complex nature of the sulfation reaction of limestone and dolomites. AIChE Journal, vol. 3, no. 30. pp. 450-457.

Chen, P., Min, M., Chen, Y., WANG, L., Li, Y., and Chen, Q. 2009. Review of the biological and engineering aspects of algae to fuels approach. International Journal of Agricultural and Biological Engineering, vol. 2, no. 4. pp.1-30.

Emami-Taba, L., Irfan, M.F., Daud, W.M.A.W., and CHAKRABARTI, M.H. 2013. Fuel blending effects on the co-gasification of coal and biomass - A review. Biomass and Bioenergy, vol. 57. pp. 249-263.

EUBA. 2007. Densification-related advantages. A Pellet Roadmap for Europe. European Biomass Association. pp.1-11.

Freund, M. 1984. Intrinsic global rate constant for the high temperature reaction of $\mathrm{CaO}$ and $\mathrm{H}_{2} \mathrm{~S}$. Industrial \& Engineering Chemistry Fundamentals, vol. 23. pp. 196-206.

HABIBI, R. 2013. Co-gasification of biomass and non-biomass feedstocks. PhD thesis, University of Calgary.

Hippo E.J. and TAndon, D. 1986. Low temperature steam-coal gasification catalysts. Fuel and Energy abstracts, vol. 37, no. 6. pp. 42(1).
JEFFREY, L.S. 2005. Characterization of coal resources of South Africa. Journal of the South African Institute of Mining and Metallurgy, vol. 105. pp. 95-102.

Jeong, H.J., Park, S.S., and Hwang, J. 2014. Co-gasification of coal-biomass blended char with $\mathrm{CO}_{2}$ at temperatures of $900-1100^{\circ} \mathrm{C}$. Fuel, vol. 116. pp. 465-470.

Jones, F.L. and PATEL, J.G. 1985. Performance of Utah bituminous coal in the UGAS gasifier. Proceedings of the Fifth EPRI Contractors Conference on Coal Gasification, Palo Alto, California, 30 October 1985. Electric Power Research Institute, Palo Alto.

Kamath, V.S. and Petrie, T.W. 1981. Path of reaction of hydrogen sulfidecarbonyl sulfide mixture with fully calcined dolomite. Environmental Science and Techology, vol. 15, no. 3. pp. 14.

Keairns, D.L., Archer, D.H., Newby, R.A., O'Niell, F.P., and Vidt, E.J. 1976. High temperature sulfur removal system development unit. American Chemical Society, Division of Fuel Chemistry. Preprint, 21. pp. 21-33. http://citeseerx.ist.psu.edu/viewdoc/download?doi=10.1.1.452.1759\&rep $=$ rep $1 \&$ type $=$ pdf

KHоO, H.H., КоРн, C.Y., SНАIK, M.S., and SHAMATT, P.N. 2013. Bioenergy coproducts derived from microalgae biomass via thermochemical conversion - Life cycle energy balance and $\mathrm{CO}_{2}$ emissions. Bioresource Technology, vol. 143. pp. 298-307.

NAHAS, N.C. 1983. Exxon catalytic coal gasification process: Fundamentals to flowsheets. Fuel, vol. 62, no. 2. pp. 239-241.

Nel S., Neomagus H.W.J.P., Bunt J.R., and Everson R.C. 2013. Improved reactivity of large coal particles by $\mathrm{K}_{2} \mathrm{CO}_{3}$ addition during steam gasification. Fuel Processing Technology, vol. 114. pp. 75-80.

PeLL, M. 1971. Reaction of hydrogen sulfide with fully calcined dolomite. PhD thesis, City University of New York.

RAdLoff, B., KirSTEn, M., and Anderson, R. 2004. Wallerawang colliery rehabilitation: the coal tailings briquetting process. Minerals Engineering, vol. 17, no 2. pp. 153-157.

Ratafia-Brown, J., Manfredo, L., Hoffmann, J. and Ramezan, M. 2002. Major environmental aspects of gasification-based power generation technologies. Final report prepared for the US Department of Energy. DEAT26-99FT20101.

https://www.netl.doe.gov/File\%20Library/research/coal/energy\%20syste ms/gasification/gasifipedia/final-env.pdf

Rehmat, A., AbBasian, M.J., Leppin, D., and BanerjeE, D.D. 1987. Reaction of calcium-based sorbents with sulfur in coal during gasification. Proceedings of the International Conference on Coal Science, Maastricht, The Netherlands.

Ren, H., Zhang, Y., FAng, Y., and WAnG, Y. 2011. Co-gasification behaviour of meat and bone meal char and coal char. Fuel Processing Technology, vol. 92. pp. 298-307.

RUTH, L.A., SQUiREs, A.M., and GrafF, R.A. 1972. Desulfurization of fuels with half calcined dolomite. First kinetic data Environmental Science and Technology, vol. 6, no.12. pp. 1009-1014. doi: 10.1021/es60071a004

SkHonde, P., MatjIE, R.H, Bunt, J.R, Strydom, C.A., and Schobert, H.H. 2009. Sulphur behaviour in the Sasol-Lurgi fixed-bed dry-bottom gasifier. Energy and Fuels, vol. 23. pp. 229-235.

STATISTICS SA. 2011. Mineral accounts for South Africa 1980-2008. Discussion document D0405.2. OCLC Number: 743298325. 63 pp.

Souires, A.M., Graff, R.A., and Pell, M. 1971. Desulfurization of fuels with calcined dolomites. Chemical Engineering Progress Symposium Series E, 67.

UNFCCC. 2001. National Inventory discard and duff coal. Summary report. cdm.unfccc.int/.../XH3I87ZW2PUQGAJKFY49BCM05TS1R6.31 pp.

Usón, S., VAlero, A., CoRreas, L., and MARTineZ, Á. 2004. Co-gasification of coal and biomass in an IGCC power plant: gasifier modeling. International Journal of Thermodynamics, vol. 7. pp. 165-175.

WAANDERS, F.B., MARX, S., and BunT, J.R. 2016. The production of a carbonaceous feedstock material from a waste carbon source. International application published under the patent cooperation treaty (PCT). World Intellectual Property Organization (27 October 2016), International patent: WO 2016/170439 A1; PCT/1B2016/050646.

WAGNER, N.J. 2008. The characterisation of weathered discard coals and their behaviour during combustion. Fuel, vol. 87. pp. 1687-1697.

ZHU, W., SonG, W., and Lin, W. 2008. Catalytic gasification of char from copyrolysis of coal and biomass. Fuel Processing Technology, vol. 89. pp. 890-896. 